\title{
Effect of reducing sensory and environmental stimuli during hospitalized premature infant sleep
}

\author{
Efeito da redução de estímulos sensoriais e ambientais no sono \\ de recém-nascidos pré-termo hospitalizados \\ Efecto de la reducción de estímulos sensoriales y ambientales en \\ el sueño de recién nacidos pré término hospitalizados
}

Kelly Cristina Sbampato Calado Orsi ${ }^{1}$, Nathalie Sales Llaguno ${ }^{2}$, Ariane Ferreira Machado Avelar ${ }^{3}$, Miriam Harumi Tsunemi ${ }^{4}$, Mavilde da Luz Gonçalves Pedreira ${ }^{3}$, Mônica Hiromi Sato ${ }^{1}$, Eliana Moreira Pinheiro ${ }^{3}$

${ }^{1}$ Universidade Federal de São Paulo, Escola Paulista de Enfermagem, Programa de PósGraduação em Enfermagem, São Paulo, SP, Brazil.

${ }^{2}$ Universidade Federal de São Paulo, Escola Paulista de Enfermagem, São Paulo, SP, Brazil.

${ }^{3}$ Universidade Federal de São Paulo, Escola Paulista de Enfermagem, Departamento de Enfermagem Pediátrica, São Paulo, SP, Brazil.

${ }^{4}$ Universidade Estadual Paulista Júlio de Mesquita Filho, Departamento de Bioestatística, Botucatu, SP, Brazil.

\section{ABSTRACT}

Objective: To compare the total sleep time of premature infant in the presence or absence of reducing sensory and environmental stimuli in the neonatal unit. Method: Longitudinal study in a Neonatal Intermediate Care Unit of a public hospital in Sao Paulo. The sample consisted of 13 premature infants. We used polysomnograph and unstructured observation for data collection. We analyzed 240 and 1200 minutes corresponding to the periods of the presence and absence of environmental management, respectively. Data were compared in proportion to the total sleep time in the two moments proposed by the study. Results: The total sleep time in periods without environmental management was on average $696.4( \pm 112.1)$ minutes and with management $168.5( \pm$ 27.9 ) minutes, proportionally premature infant slept an average of $70.2 \%$ during periods with no intervention and $58.0 \%$ without management $(\mathrm{p}=0.002)$. Conclusion: Reducing stimulation and handling of premature infant environment periods was effective to provide greater total sleep time.

\section{DESCRIPTORS}

Sleep; Infant, Premature; Infant, Newborn; Neonatal Nursing; Nursing Care. 


\section{INTRODUCTION}

The estimate of premature births in Brazil is about $9.8 \%$ of the $2,913.160$ births registered in $2011^{(1)}$. Due to prematurity, the proportion of premature infants (PI) may require hospitalization in a neonatal unit, which is commonly characterized as in environment that has high sensory stimuli overload for the newborn, additionally, there is a need for frequent management for invasive and painful procedures ${ }^{(2-5)}$. The characteristics of the neonatal unit environment and care provided to premature infants according to the institutional routines can reduce the total sleep time leading them to consequent deprivation, which can be constituted in morbidity factor, especially when the gestational age is low and the length of hospital stay is long ${ }^{(2,4,6)}$.

Many studies show that sleep deprivation of premature infants in the neonatal unit can lead to worsening of clinical status and delay hospital discharge, besides that, it could trigger behavioral disorders in adulthood ${ }^{(4,7-8)}$. PI present sleep with polyphasic pattern that are classified into three stages: active, quiet and indeterminate sleep ${ }^{(3,7,9-10)}$. The different stages of sleep are essential for the homeostasis of premature infants, because they establish relations with important physiological and neurological activities ${ }^{(3,9)}$. In the quiet sleep, decreased basal metabolic rate occurs, which promotes replenishment of energy reserves as well as promote cellular repair, in the active sleep brain activation occurs, which is essential for the structural maturation of the central nervous system $^{(10-11)}$. It is noteworthy that the indeterminate sleep cannot be considered as quiet or active, it is characterized as the transition between these two types of sleep patterns ${ }^{(12)}$. Mitigating possible harmful effects of care provided to hospitalized newborns is one of the actions that should be prioritized by professionals working towards recovery ${ }^{(13)}$.

In this context, the developmental care aims at reducing stress to hospitalized newborns, recommending actions in order to minimize the impact of the various deleterious effects caused by the environment and care for newborns ${ }^{(2,5,14)}$. Among the strategies recommended by the developmental care, there is the management of the neonatal unit environment, which is characterized by reduced sensory and environmental stimuli to newborns. This intervention is commonly called nap time and is intended to promote sleep and rest for newborns, from the reduction of noise level, brightness and handling at certain periods of the day ${ }^{(15)}$.

Considering the importance of sleep to children's development and the existence of that strategy in the neonatal unit environment in our work, we questioned whether this intervention carries some effect on sleep of hospitalized premature infants. Thus, this study aims to compare the total sleep time of hospitalized premature infants between periods of presence and absence of management of a Neonatal Intermediate Care Unit (NICU).

\section{METHOD}

Longitudinal study conducted in a NICU of a public hospital in Sao Paulo. It has two rooms for a total of 15 beds which are intended for hospitalization of pre-term, term, and post-term infants. In both environments there is presence of both artificial and natural lighting due to the existence of transparent glass windows viewing to the nursery corridor and public roads. While assisting newborns in the NICU some equipment is commonly employed, which produces noises such as multiparameter monitor, incubator, heated cradle and infusion pump. The health service has a multidisciplinary team of nurses, nursing technicians and assistants, physicians, physiotherapists, psychologists, social workers, speech therapists, administrative and support assistants. In general, also circulating the NICU are professors, nursing undergraduate students, medical residents and parents whose presence is allowed full time.

In the two rooms of the NICU are provided daily, four environmental management periods whose schedules were set according to the routines of the service. This intervention is called nap time. In general, this intervention takes place in the mornings from 10:00am to $11: 00 \mathrm{am}$, in the afternoon from $05: 00 \mathrm{pm}$ to $06: 00 \mathrm{pm}$ and in the evening on two moments, one from 11:00pm to 12:00am (Night I) and the other from 4:00am to 5:00am (Night II).

The convenience sample consisted of 13 premature infants due to the time and resources available for research. The subjects selected for the study met the following inclusion criteria: the authorization and signature of the Consent Form provided by the family or responsible for the neonate; PI who were inside the incubator; had current weight between 1200-2000 grams; presented results of the optoacoustic emission test evoked by transient stimulus, after evaluation of the speech therapist service; had appropriate cardiorespiratory parameters for gestational age; did not use intravenous therapy; were fed by oral and/or enteral route. We excluded premature infants that: were using depressant medication of the central nervous system and steroids in the last 72 hours; who were under phototherapy; made use of invasive or noninvasive ventilation; had congenital malformation and periventricular hemorrhage grades II, III and IV; had mothers who had used illicit drugs during pregnancy. It is noteworthy that the exclusion criteria were adopted in order to prevent the influence of pathological factors and/or treatment on sleep of the subjects.

Data were collected from October 2012 to May 2013, after they met national and international standards of ethics in research involving human beings and approved by the Research Ethics Committee of the institution (CEP No. 19387/CAEEE No. 01498912.6. 0000.5505).

We used the polysomnograph model Alice 5 (Respironics ${ }^{\circledR}$ ) and unstructured observation for data collection, which was held on different days of the week, during 24 uninterrupted hours. The polysomnograph was settled in premature infants by a polysomnograph technician (PT), and all sleep records were analyzed by a neurologist expert in sleep medicine that has met the guidelines of the American Academy of Sleep Medicine (AASM) version $2^{(16)}$. The unstructured observation was performed by the researchers and PT, who were previously trained to make all records in order to assist in the interpretation of raw data generated by polysomnograph and also the results obtained. So, there 
were some aspects of the behavior of premature infants that were registered, such as: presence of eye movements, movement of the upper and lower limbs, eyes open or closed and crying. In addition, we also recorded data on handling of PI by professionals or family during data collection and also in the NICU environment, such as: presence/absence of noise, artificial and/or natural lighting both inside the rooms and in the nursery corridor. In order to make the precise cutouts of each polysomnography at different periods of environmental management, the start and end periods of the intervention were noted by the researchers to analyze the data concerning the sleep of premature infants.

Were analyzed 24 hours of sleep and wakefulness records of each subject involved in the study, 20 hours (1200 minutes) corresponding the periods that there was no environmental management in the NICU investigated and 4 hours (240 minutes) for the four different periods of environmental management, totaling 1440 minutes.

For characterization of premature infants, we evaluated gestational age (GA) according to New Ballard (NB), corrected by chronological, sex and weight at birth and at the period of the study.

Data were compiled in a spreadsheet and analyzed in SPSS Statistics 17.0 software. To perform the statistical analysis we used the Student $t$ test for dependent samples because the same PI was evaluated at moments when environmental management occurred or not and were also observed that the analyzed sleep time followed a normal distribution (Kolmogorov-Smirnov test). Due to the difference between the durations of the periods of presence and absence of environmental management, compared to the total time of sleep of premature infant in these two periods, calculating all percentages in relation to 60 minutes. Thus, each hour referring to the time of the intervention in the environment was compared to another 300 remaining minutes, representing the other 5 hours, totaling the duration of six hours of each period analyzed. After evaluating the normality of the percentages obtained, the $t$ test for dependent samples was used to compare the mean percentage values between the moments that occurred or not the environmental management. We considered as statistically significant $\mathrm{p} \leq 0.05$.

\section{RESULTS}

The newborns of the sample were classified as moderate premature infants, they had an average of eight days old, were predominantly male, and had low weight at birth and also at the time of the study, according to the data presented in Table 1.

Table 2 shows the average in minutes and the relative frequencies of total sleep time of the PI and the respective stages in the presence or absence of environmental management in the Neonatal unit.

Analyzing the proportion of sleep time of the PI in the presence or absence of environmental management, it is observed that when the intervention occurred, PI had, on average, an increase of $12.2 \%$ in total sleep time, which was statistically significant $(\mathrm{p}=0.002)$, as shown in Table 2 . As for sleep stages of the analyzed premature infants, we observed that the quiet sleep was the most frequent for both moments in the presence and absence of environment intervention. It was also found that the reduction of sensory and environmental stimuli, the proportion of time that the PI presented this same sleep stage was $9.9 \%$ higher than in periods without intervention, observing a statistically significant difference $(\mathrm{p}=0.001)$.

Table 1 - Characteristics of premature infants hospitalized in the neonatal unit - Sao Paulo, October 2012 to May 2013.

\begin{tabular}{lcc}
\hline Variables & Mean \pm SD & $\mathbf{n}-\%$ \\
\hline Gestational age (weeks) & $33.2 \pm 1.9$ & $12-100$ \\
NB & $34.6 \pm 1.8$ & $12-100$ \\
Adjusted & $9.3 \pm 6.1$ & $12-100$ \\
Chronological age (day) & - & \\
Gender (\%) & - & $8-38.5$ \\
Female & & \\
Male & $1742 \pm 226$ & $12-100$ \\
Weight (grams) & $1760 \pm 173.4$ \\
At birth & \\
At the time of study & & \\
\hline
\end{tabular}

Legend: NB: gestational age based on classification according to the New Ballard; SD: standard deviation.

Table 2 - Average minutes and the relative frequencies of total sleep time of premature infants and their sleep stages, with and without reducing sensory and environmental stimuli of neonatal unit - Sao Paulo, October 2012 to May 2013.

\begin{tabular}{|c|c|c|c|c|c|}
\hline \multirow{3}{*}{ Variables } & \multicolumn{4}{|c|}{$\begin{array}{l}\text { Reduction of sensory and } \\
\text { environmental stimuli }\end{array}$} & \multirow{3}{*}{ P value* } \\
\hline & \multicolumn{2}{|c|}{$\begin{array}{c}\text { Yes } \\
\mathrm{n}=13 / 240 \\
\text { minutes }\end{array}$} & \multicolumn{2}{|c|}{$\begin{array}{c}\text { No } \\
\mathrm{n}=13 / 1200 \\
\text { minutes }\end{array}$} & \\
\hline & Mean/SD & $\% 1$ & Mean/SD & $\%^{1}$ & \\
\hline $\begin{array}{l}\text { Total sleep } \\
\text { time }\end{array}$ & $168.5 \pm 27.9$ & 70.2 & $\begin{array}{c}696.4 \\
\pm 112.1\end{array}$ & 58.0 & 0.002 \\
\hline Active sleep & $50.3 \pm 19.8$ & 21.0 & $224.6 \pm 78.1$ & 18.7 & 0.406 \\
\hline Quiet sleep & $81.0 \pm 30.8$ & 33.8 & $\begin{array}{c}287.4 \\
\pm 144.7\end{array}$ & 23.9 & 0.001 \\
\hline $\begin{array}{l}\text { Indeterminate } \\
\text { sleep }\end{array}$ & $37.1 \pm 14.5$ & 15.5 & $184.4 \pm 67.9$ & 15.4 & 0.930 \\
\hline
\end{tabular}

Legend: $1:{ }^{1}$ Time, in percentage, that the PI spent in each sleep stage in proportion to the period analyzed; *P value refers to the comparison of the percentages obtained in the hatched columns.

Table 3 show the averages in minutes and the relative frequencies of total sleep time of premature infants and their sleep stages in four different periods analyzed in the presence or absence of environmental management in the neonatal unit.

Based on the four different periods analyzed, we observed that at times when there was a reduction of sensory and environmental stimuli in the NICU, premature infants presented higher mean total sleep time in the morning and in the absence of that intervention, it was observed that the average total sleep time of PI had no difference. In the mornings, we identified a $21.3 \%$ increase in total sleep time of premature infants when there was environmental 
management observing a statistically significant difference $(\mathrm{p}<0.001)$. In the afternoon period, we also observed an increase of $17.5 \%$ in total sleep time of PI in the environmental management, resulting in a statistically significant difference $(\mathrm{p}=0.021)$, which was not identified in the two night periods (Table 3 ).

Table 3 - Average minutes and the relative frequencies of total sleep time and their sleep stages for periods of the day, according to the presence or absence of sensory reduction and environmental stimuli in the neonatal unit - Sao Paulo, October 2012 to May 2013.

\begin{tabular}{|c|c|c|c|c|c|}
\hline \multirow{3}{*}{ Variables } & \multicolumn{4}{|c|}{$\begin{array}{c}\text { Reduction of sensory and environmental } \\
\text { stimuli }\end{array}$} & \multirow{3}{*}{ P value* } \\
\hline & \multicolumn{2}{|c|}{$\begin{array}{c}\text { Yes } \\
n=13 / 60 \text { minutes }\end{array}$} & \multicolumn{2}{|c|}{$\begin{array}{l}\text { No } \\
n=13 / 300 \text { minutes }\end{array}$} & \\
\hline & Mean / SD & $\%^{1}$ & Mean / SD & $\%^{1}$ & \\
\hline \multicolumn{6}{|l|}{ Morning ${ }^{1}$} \\
\hline Total sleep time & $47.4 \pm 10.3$ & 79.0 & $173.2 \pm 38.5$ & 57.7 & $<0.001$ \\
\hline Active sleep & $10.7 \pm 7.5$ & 17.9 & $50.5 \pm 24.6$ & 16.8 & 0.755 \\
\hline Quiet sleep & $28.0 \pm 13.5$ & 46.7 & $77.4 \pm 38.2$ & 25.8 & 0.000 \\
\hline $\begin{array}{l}\text { Indeterminate } \\
\text { sleep }\end{array}$ & $8.7 \pm 4.4$ & 14.5 & $45.3 \pm 20.6$ & 15.1 & 0.733 \\
\hline \multicolumn{6}{|l|}{ Afternoon ${ }^{2}$} \\
\hline Total sleep time & $45.8 \pm 10.4$ & 76.3 & $176.5 \pm 45.2$ & 58.8 & 0.021 \\
\hline Active sleep & $13.3 \pm 9.3$ & 22.2 & $55.5 \pm 19.0$ & 18.5 & 0.456 \\
\hline Quiet sleep & $20.4 \pm 14.7$ & 34.0 & $77.2 \pm 43.0$ & 25.7 & 0.283 \\
\hline $\begin{array}{l}\text { Indeterminate } \\
\text { sleep }\end{array}$ & $12.0 \pm 5.9$ & 20.0 & $43.8 \pm 18.5$ & 14.6 & 0.054 \\
\hline \multicolumn{6}{|l|}{ Night $I^{2}$} \\
\hline Total sleep time & $36.3 \pm 18.6$ & 60.4 & $172.7 \pm 38.4$ & 57.6 & 0.744 \\
\hline Active sleep & $12.2 \pm 10.8$ & 20.4 & $60.4 \pm 34.7$ & 20.1 & 0.969 \\
\hline Quiet sleep & $16.1 \pm 10.6$ & 26.9 & $62.0 \pm 31.4$ & 20.7 & 0.210 \\
\hline $\begin{array}{l}\text { Indeterminate } \\
\text { sleep }\end{array}$ & $7.9 \pm 6.6$ & 13.2 & $50.3 \pm 15.8$ & 16.8 & 0.279 \\
\hline \multicolumn{6}{|l|}{ Night II' } \\
\hline Total sleep time & $39.0 \pm 13.3$ & 65.0 & $173.9 \pm 46.9$ & 58.0 & 0.242 \\
\hline Active sleep & $14.0 \pm 12.3$ & 23.4 & $58.1 \pm 32.1$ & 19.4 & 0.394 \\
\hline Quiet sleep & $16.5 \pm 11.5$ & 27.4 & $70.8 \pm 48.6$ & 23.6 & 0.363 \\
\hline $\begin{array}{l}\text { Indeterminate } \\
\text { sleep }\end{array}$ & $8.5 \pm 5.3$ & 14.2 & $45.0 \pm 22.9$ & 15.0 & 0.682 \\
\hline
\end{tabular}

Legend: ${ }^{1}$ Time, in percentage, that the PI spent in each sleep stage in proportion to the period analyzed; ${ }^{2}$ period analyzed; ${ }^{*} \mathrm{P}$ value refers to the comparison of the percentages found in the hatched columns.

Analyzing the three stages of sleep of preterm infants in the four distinct periods of the day, it was found that quiet sleep was the most prevalent followed by active and indeterminate, both in the presence and absence of environmental management in the NICU. It is noteworthy that the quiet sleep had statistically significant difference $(\mathrm{p}=0.000)$ in the mornings between both periods, as can be seen in Table 3 .

\section{DISCUSSION}

PI slept proportionally longer regarding environmental management in the NICU in all periods analyzed. Thus, it could be seen that the reduction of sensory and environmental stimuli of the NICU is effective for the purpose to which it is proposed, when comparing the periods in which no intervention was performed. This result reinforces the importance of this care in the neonatal unit investigated for promoting sleep, since there are few publications in the literature that assess health promotion actions of hospitalized infants sleep. Furthermore, it emphasizes the importance of this study for clinical practice, since the nap time was defined by care demands of the service. The possible increase of the evaluated intervention, increasing the duration and frequency of nap time will favor the service of this important basic human need, which is the sleep and rest of newborns.

A study indicates that it is essential to establish a peaceful environment in the neonatal unit, in particular, to increase the sleep time of newborns, monitoring heart and respiratory rates and allowing peace moments for the baby with his/her family ${ }^{(17)}$. The data obtained through observations revealed that most of the time the door of the neonatal unit remained open during sleep records on the absence of the environment management, allowing noise and artificial lighting of the hall to enter the NICU, adding up to the existing presence of natural light from the rooms. It was also noted that during nap time, noise, lighting from the corridor and inside the rooms, and also the management of newborns were minimized. It is possible that such data can explain the statistical significance observed in average total sleep time of PI during the nap time.

Researches that aimed to assess the impact of environmental management on sleep of hospitalized premature infants using the polysomnograph in two periods of 180 minutes, found a $20 \%$ increase in total sleep time when covered the incubators to reduce the incidence of light and also when kept room door closed in order to minimize noise ${ }^{(7,14)}$.

Although nap time proposed by the NICU have been effective in promoting sleep of those premature infants investigated, the results allow concluding that in the remaining 20 hours there was no environmental management, total sleep time was only 11.6 hours. Proportionally, this finding shows that the total sleep time of newborns was lower than recommended by the literature, which highlights they require 17-22 hours of sleep, depending on gestational age ${ }^{(18-19)}$. The data from observations allowed us to infer that the total sleep time was lower in the absence of environment management due to handling of newborns by unit staff and cry arising from care, which may have boosted the increase in the noise level and the consequent environmental acoustics change in general. This result also indicates that premature infants are being deprived of sleep, which can cause various deleterious effects such as stress, irritability, increased heart rate, basal metabolism with consequent weight loss, increased susceptibility to infections and changes in pain perception ${ }^{(14,18,20)}$. Sleep deprivation may be related to the impairment of sick children, generating an increase in hospitalization costs and delaying hospital discharge ${ }^{(20)}$.

Thus, the results of the total sleep time of PI in periods where there is no environmental management indicate the need for the implementation of other care protocols for clinical practice in order to promote and protect the sleep of hospitalized neonates facing their demands in context 
of individualized care. Current research suggests that the nursing staff should develop protocols in order to promote a safe sleep environment in neonatal units ${ }^{(21)}$.

The evolution of the available knowledge and technology used in newborn care resulted in numerous deleterious effects on their development. Thus, there is the need for nurses to be aware of the importance of reconciling the care of newborns with the environment in order to preserve its development ${ }^{(22)}$.

In this study, the quiet sleep was the most frequent for both presence and absence of environmental management, followed by active and indeterminate sleep. The literature data suggest that active sleep, during which occur significant brain activity responsible for sensorineural development and learning corresponding to $60-80 \%$ of total sleep time between neonates with 28-32 weeks of gestational age $\mathrm{e}^{(18,21)}$. This proportion decreases as neurological maturation occurs when one observes an increase in quiet sleep time, essential for the restoration of body ${ }^{(9,18,23-24)}$. It is inferred that this finding can be explained by the maturity of the subjects, who were classified as moderate premature infants.
This prospective study aimed to evaluate the effect of developmental care on the quiet sleep of preterm infants with GA of less than 32 weeks and with very low weight at birth, it showed that the subjects investigated did not undergo such care showed significant variation in total time of quiet sleep, which allowed us to infer that the environmental management intervention protects sleep ${ }^{(25)}$.

\section{CONCLUSION}

We conclude that the total sleep time of PI was higher in environmental management periods when compared to no environmental control. The quiet sleep of PI was the predominant sleep stage both in the presence and absence of environmental management. A limitation of the study consisted in the sample size because of the resources that were available. This study advanced towards having evaluated a nursing intervention in which records regarding sleep of preterm infants were obtained for 24 uninterrupted hours, through polysomnograph, which is considered gold standard instrument for making sleep analysis in neonates.

\section{RESUMO}

Objetivo: Comparar o tempo total de sono dos recém-nascidos pré-termo na vigência ou não da redução de estímulos sensoriais e ambientais da unidade neonatal. Método: Estudo longitudinal realizado em uma Unidade de Cuidados Intermediários Neonatal de hospital público de São Paulo. A amostra constituiu-se de 13 pré-termos. Utilizou-se o polissonígrafo e a observação não estruturada para coleta de dados. Foram analisados 240 minutos e 1200 minutos correspondentes aos períodos da presença e ausência do manejo ambiental, respectivamente. Os dados foram comparados proporcionalmente aos tempos totais de sono nos dois momentos propostos pelo estudo. Resultados: Mostraram que o tempo total de sono nos momentos sem manejo ambiental foi em média de 696,4 ( $\pm 112,1)$ minutos e com manejo de $168,5( \pm 27,9)$ minutos, sendo que proporcionalmente os prematuros dormiram em média 70,2\% nos períodos com intervenção e 58,0\% sem o manejo ( $\mathrm{p}=0,002)$. Conclusão: A redução do estímulo e da manipulação dos prematuros nos períodos de manejo do ambiente foi eficaz para proporcionar maior tempo total de sono.

\section{DESCRITORES}

Sono; Prematuro; Recém-Nascido; Enfermagem Neonatal; Cuidados de Enfermagem.

\section{RESUMEN}

Objetivo: Comparar el tiempo total de sueño de los recién nacidos pré término en la vigencia o no de la reducción de estímulos sensoriales y ambientales de la unidad neonatal. Método: Estudio longitudinal realizado en una Unidad de Cuidados Intermedios Neonatal de hospital público de São Paulo. La muestra se constituyó de 13 pre términos. Se utilizó el polisonógrafo y la observación no estructurada para la recogida de datos. Fueron analizados 240 minutos y 1200 minutos correspondientes a los períodos de la presencia y ausencia del manejo ambiental, respectivamente. Los datos fueron comparados proporcionalmente a los tiempos totales de sueño en los dos momentos propuestos por el estudio. Resultados: Mostraron que el tiempo total de sueño en los momentos sin manejo ambiental fue en promedio de $696,4( \pm 112,1)$ minutos y con manejo de $168,5( \pm 27,9)$ minutos, siendo que proporcionalmente los prematuros durmieron en promedio el 70,2\% en los períodos con intervención y el 58,0\% sin el manejo ( $\mathrm{p}=0,002)$. Conclusión: La reducción del estímulo y el mantenimiento de los prematuros en los períodos de manejo del ambiente fueron eficaces para proporcionar mayor tiempo total de sueño.

\section{DESCRIPTORES}

Sueño; Prematuro; Recién Nacido; Enferméria Neonatal; Atención de Enfermería.

\section{REFERENCES}

1. Brasil. Ministério da Saúde. DATASUS. Informações em Saúde. Nascidos vivos - Brasil [Internet]. Brasília; 2014 [citado 2014 set. 25]. Disponível em: http://tabnet.datasus.gov.br/cgi/tabcgi.exe?sinasc/cnv/nvuf.def

2. Vandenberg KA. Individualized developmental care for high risk newborns in the NICU: a practice guideline. Early Hum Dev. 2007;83(7):433-42.

3. Foreman SW, Thomas KA, Blackburn ST. Preterm infant state development: individual and gender differences matter. J Obstet Gynecol Neonatal Nurs. 2008;37(6):657-65. 
4. Salgado APA, Adirson DM, La Cava AM, Camacho KG. O sono do recém-nascido em unidade de terapia intensiva neonatal. Rev Enferm UERJ. 2011;19(4):644-9.

5. Santos AO. NIDCAP ${ }^{\circledR}$ : uma filosofia de cuidados. Nascer Crescer 2011; 20(1):26-31.

6. Weisman O, Magori-Cohen R, Louzoun Y, Eidelman Al, Feldman R. Sleep-wake transitions in premature neonates predict early development. Pediatrics. 2011;128(4):706-14

7. Bertelle V, Mabin D, Adrien J, Sizun J. Sleep of preterm neonates under developmental care or regular environmental conditions. Early Hum Dev. 2005;81(7):595-600.

8. Sevestre A, Oger E, Bertelle V, Mabin D, Sizun J. Agreement between behavioural observation and polygraphy for the diagnosis of sleepwake states in preterm neonates. Acta Paediatr. 2013;102(5):229-31.

9. Ednick M, Cohen AP, McPhail GL, Beebe D, Simakajornboon N, Amin RS. A review of the effects of sleep during the first year of life on cognitive, psychomotor, and temperament development. Sleep. 2009;32(11):1449-58.

10. Graven SN, Browne JV. Sleep and brain development: the critical role of sleep in fetal and early neonatal brain development. Newborn Infant Nurs Rev. 2008;8(4):173-9.

11. Geib LTC. Desenvolvimento dos estados de sono na infância. Rev Bras Enferm. 2007;60(3): 323-6.

12. Iber C, Ancoli-Israel S, Chesson A, Quan SF. The AASM manual for the scoring of sleep and associated events: rules, terminology and technical specifications. Westchester: American Academy of Sleep Medicine; 2007.

13. Colombo G, Bon GD. Strategies to protect sleep. J Matern Fetal Neonatal Med. 2011; 24 (S(1)):30-1.

14. Bertelle V, Sevestre A, Laou-Hap K, Nagahapitiye MC, Sizun J. Sleep in the neonatal intensive care unit. J Perinat Neonat Nurs. 2007;21(2):140-8.

15. Brasil. Ministério da Saúde; Secretaria de Atenção à Saúde, Departamento de Ações Programáticas Estratégicas. Atenção humanizada ao recém nascido de baixo peso: método Canguru. $2^{\text {a }}$ ed. Brasília: Ed. Ministério da Saúde; 2011.

16. American Academy of Sleep Medicine. International Classification of Sleep Disorders, revised. Diagnostic and coding manual. 2th ed. Westchester: AASM; 2005.

17. Shahheidari $M$, Homer $C$. Impact of the design of neonatal intensive care units on neonates, staff, and families: a systematic literature review. J Perinat Neonat Nurs. 2012;26(3):260-6.

18. Calciolari G, Montirosso R. The sleep protection in the preterm infants. J Matern Fetal Neonatal Med. 2011;24 Suppl 1:12-4.

19. So K, Adamson TM, Horne RSC. The use of actigraphy for the assessment of the development of sleep/wake patterns in infants during the first 12 months of life. J Sleep Res. 2007;16(2):181-7.

20. Gaíva MAM, Marquesi MC, Rosa MKO. O sono do recém-nascido internado em unidade de terapia intensiva: cuidados de enfermagem. Ciênc Cuid Saúde. 2010;9(3):602-9.

21. Lacina L, Casper T, Dixon M, Harmeyer J, Haberman B, Alberts JR, et al. Behavioral observation differentiates the effects of an intervention to promote sleep in premature infants: a pilot study. Adv Neonatal Care. 2015;15(1):70-6.

22. Colombo G, De Bon G. Strategies to protect sleep. J Matern Fetal Neonatal Med. 2011;24 Suppl 1:30-1.

23. Heraghty JL, Hilliard TN, Henderson AJ, Fleming PJ. The physiology of sleep in infants. Arch Dis Child. 2008;93(11):982-5.

24. Bonan KCSC, Pimentel Filho JC, Tristão RM, Jesus JAL, Campos Junior D. Sleep deprivation, pain and prematurity: a review study. Arq Neuro-Psiquiatr. 2015;73(2):147-54.

25. Westrup B, Hellström-Westas L, Stjernqvist K, Lagercrantz H. No indications of increased quiet sleep in infants receiving care based on the newborn individualized developmental care and assessment program (NIDCAP). Acta Paediatr. 2002;91(3):318-22.

Funding: Sao Paulo Research Foundation (FAPESP). Process N 2012/50365-2. 